\title{
Treatment compliance in adults with cystic fibrosis
}

\author{
J Abbott, M Dodd, D Bilton, A K Webb
}

\begin{abstract}
Background - The study comprised three interrelated aims: (1) to ascertain (a) patient compliance with physiotherapy, exercise, enzyme and vitamin regimens, (b) how compliance was perceived by patients, and (c) the reasons for poor compliance; (2) to identify demographic and clinical variables associated with compliance; and (3) to determine how accurately patient compliance can be predicted by carers.
\end{abstract}

Methods - Demographic and medical history data were obtained from medical records and a patient questionnaire. The data obtained included age, sex, employment status, inpatient or outpatient status, frequency of contact with the clinic, age at diagnosis, and the number of years practising physiotherapy. Measures of clinical status, including $\mathrm{FEV}_{1}$ and FVC percentage predicted, Shwachman score, and 24 hour sputum weight were recorded before completion of the questionnaire. The questionnaire, administered by a psychologist, assessed the reported degree of patient compliance, their perception of compliance, and their reasons for poor compliance.

Results - Sixty patients participated in the study and $51 / 60$ and $41 / 55$ patients were considered compliant with enzyme and exercise therapies, respectively. Compliance was lower with physiotherapy $(32 / 60)$ and vitamin treatment (21/ 45). Patients reporting immediate benefits following exercise and physiotherapy were more compliant than those reporting no improvement. The perception by patients that compliance was sufficient ("about right") was physiotherapy $67 \%$, exercise $37 \%$, enzymes $78 \%$, and vitamins $\mathbf{9 \%}$. Compliance was not influenced by demographic details nor by severity of disease, although patients producing large amounts of sputum and receiving help with physiotherapy were more compliant with physiotherapy. The physiotherapist and physician judged correctly the degree of compliance with physiotherapy in $83 \%$ and $75 \%$ of cases, respectively, and with exercise in $68 \%$ and $67 \%$ of cases, respectively.

Conclusions - The reported degree of compliance and reasons for poor compliance were treatment specific. Demographic and disease severity variables were not associated with compliance. Those involved in the care of patients with cystic fibrosis were able to predict patient compliance.

(Thorax 1994;49:115-120)

An increasing number of patients with cystic fibrosis are surviving into adulthood; this has been attributed to earlier diagnosis, specialist care, and more effective methods of treatment. ${ }^{1-4}$ Compliance, defined as the degree of patient adherence to medical advice and treatment regimens, may be an important factor in the successful management of the disease.

The daily management includes physiotherapy, exercise, oral and inhaled medication for the respiratory system, and oral pancreatic enzymes and vitamin supplements for the control of malabsorption. Those patients awaiting heart-lung transplantation may additionally need to manage home gastrostomy feeding and nocturnal ventilation. A complex and time consuming regimen of self care is therefore expected of the patient.

There is no conclusive link between poor compliance with treatment and progressive disease in cystic fibrosis. However, non-compliance with treatment and medical advice may cause accelerated disease, wasted resources, increased outpatient visits, and more admissions to hospital, and the ability to predict the effectiveness of treatment may be impaired.

Previous studies of compliance have concentrated on children using parental reporting, or have been confounded by combining the results of children and adults. ${ }^{5-7}$ Little attention has been given to adults who are often striving for independence with their management regimens. In addition, these studies have suffered from poor experimental design, with data obtained whilst in hospital or from medical records, and use of insensitive scoring systems. Most have assessed several treatment regimens but have combined the data to provide an overall score, thereby losing specific treatment data. ${ }^{7-9}$ An overall compliance score fails to recognise that patients may comply, to varying degrees, with different components of a treatment regimen. In a study of adult patients with cystic fibrosis $76 \%$ took their prescribed drugs $90 \%$ of the time, while only $54 \%$ of patients adhered to their physiotherapy regimens and $57 \%$ to their exercise regimens. ${ }^{10}$

In order to improve compliance, factors which predict compliance need to be identified, together with the reasons for poor adherence. This study aimed to investigate these areas in adults with cystic fibrosis. 
Methods

SUBJECTS

Consecutive patients attending the Monsall Adult Cystic Fibrosis Unit were invited to take part in the study. It was intended to recruit half the patients attending the unit, and 67 patients were approached.

\section{INTERVIEW}

Each patient was interviewed during a period of clinical stability by a psychologist and guided through the compliance questionnaire (see appendix on page 120). The accuracy of the interview was validated by asking a close companion (usually mother or partner) questions phrased in a similar manner about the patient's degree of compliance. To minimise the "faking of good effect" by patients, interviews were conducted away from the wards or treatment areas by those not directly involved in patient treatment. The importance of confidentiality was emphasised.

\section{QUESTIONNAIRE}

There are no published measures of compliance with treatment appropriate for cystic fibrosis. A questionnaire was designed by the authors that measured three aspects of compliance for each of the four treatment components: physiotherapy, exercise, pancreatic enzymes, and vitamins. The three aspects of compliance were (1) the degree of adherence to medical advice or treatment; (2) patient perception of whether treatment was sufficient; and (3) the reasons for non-compliance.

\section{Measures of degree of compliance with treatment}

(a) Physiotherapy: adherence with physiotherapy was measured on a six point scale (question 5, appendix).

(b) Exercise: patients were asked three questions about their level and frequency of exercise (questions 8,9 , and 10 , appendix). The degree of benefit was assessed by the physiotherapist according to the exercise capacity based on exercise testing and disease severity. (c) Enzymes: questions related to enzymes taken with main meals and those taken with snacks were scored on a four point scale (questions 13 and 16, appendix).

(d) Vitamins: adherence with vitamins was marked on a four point scale (question 22, appendix).

The questionnaire also included general questions for some treatments - for example "do you have help with your physiotherapy," "do you feel better following physiotherapy and exercise," "are you prescribed vitamins?" The timing of pancreatic enzyme administration during meals was also ascertained (appendix).

Measures of patient perception of compliance For each treatment modality patients were asked to choose from one of four statements: "about right," "not enough," "too much," and "don't know" (questions 7, 12, 18, and 24, appendix).

\section{Measures of patient reasons for poor compliance}

Patients selected their reasons for poor compliance from a list for each of the four treatments (appendix). They were also encouraged to add other reasons of their choice.

\section{Self prescribed medication}

Details of frequency and type of self prescribed medication were collected (questions 25-27, appendix).

\section{DEMOGRAPHIC DATA}

Medical history

Details of age, sex, employment status, and age at diagnosis were obtained from medical records. The number of clinic visits in the previous year and contact with carers for inpatient and outpatient treatment was compared. The number of years of practising physiotherapy and any help received with physiotherapy were validated by patients' responses to the questionnaire.

\section{Clinical measures}

At the time the questionnaire was administered each patient was seen by two physicians to obtain a Shwachman score. Measurements were made of respiratory function $\left(\mathrm{FEV}_{1} \%\right.$ predicted and FVC \% predicted) and 24 hour sputum weight $(>35 \mathrm{~g} /$ day $=$ large volume sputum producer, $<35 \mathrm{~g} /$ day $=$ small volume sputum producer).

\section{PREDICTORS OF COMPLIANCE}

A predicted degree of compliance with physiotherapy and exercise was made independently by the physiotherapist and physician on a similar scale to that completed by the patient.

\section{STATISTICAL ANALYSES}

Data analyses were performed with the Statistical Package for the Social Sciences (SPSS). Associations between the degree of compliance and demographic and clinical variables were analysed by the $\chi^{2}$ test. Comparisons between patients and close companions were tested by the Mann-Whitney $U$ test.

\section{Results}

Of the 67 patients, 25 women and 35 men completed the questionnaire and seven declined to take part. There were no demographic or medical differences between the participating and non-participating patients. The mean age and $\mathrm{FEV}_{1} \%$ predicted of the patients in the study were 20.98 years (range $16-44$ ) and $59.4 \%$ (range 10-103\%) respectively. All study population means and percentages were 
Table 1 Reported degrees of compliance with physiotherapy, exercise, enzyme, and vitamin regimens by patients and close companions

\begin{tabular}{lrr}
\hline Degree of compliance & Patients & Close companions \\
\hline Physiotherapy ( $\mathrm{n}=60):$ & & \\
Once or twice per day & $19(32)$ & $21(35)$ \\
Occasionally miss & $13(21)$ & $13(21)$ \\
Often miss one or two days & $4(7)$ & $5(8)$ \\
Often miss many days & $6(10)$ & $5(8)$ \\
Only when ill & $10(17)$ & $7(12)$ \\
Never & $8(13)$ & $9(15)$ \\
Exercise (n=55): & & \\
Exercising beneficially & $41(75)$ & $38(69)$ \\
Not exercising & $14(25)$ & $17(31)$ \\
Enzymes (n=60): & & \\
Always & $51(85)$ & $56(93)$ \\
Usually & $7(12)$ & $4(7)$ \\
Occasionally & $2(3)$ & $0(0)$ \\
Never & $0(0)$ & $0(0)$ \\
Vitamins (n=45): & & \\
Always & $21(47)$ & $25(56)$ \\
Usually & $16(36)$ & $18(40)$ \\
Occasionally & $7(15)$ & $2(4)$ \\
Never & $1(2)$ & $0(0)$ \\
\hline
\end{tabular}

Values in parentheses are percentages.

representative of the total population attending the Monsall Adult Cystic Fibrosis Unit.

\section{INTERVIEW}

No significant differences emerged between the responses of patients and their close companions for the four treatment regimens.

\section{MEASURES OF COMPLIANCE}

Degree of compliance (table 1)

(a) Physiotherapy: the six compliance categories were condensed into three groups, giving 32 patients who were considered compliant, 10 partially compliant, and 18 patients who were non-compliant.

(b) Exercise: five of the 60 patients did not perform exercise because of the severity of their disease. Of the remainder 41 were considered to be exercising beneficially by the physiotherapist, with 14 failing to reach a beneficial level. From the general questions 28 and 35 patients reported that their chest felt better following physiotherapy and exercise, respectively. They also complied with exercise to a greater degree than patients reporting no improvement $(\mathrm{p}<0.01)$.

(c) Enzymes: most patients $(\mathrm{n}=51)$ always took enzymes with main meals, seven usually did, and two occasionally complied with the treatment regimen. The taking of enzymes with snacks revealed a poor degree of compliance: 13 patients always took enzymes with snacks, 27 usually did, 14 occasionally did, and six never did. Over half the patients $(53 \%)$ consumed the enzymes throughout the meal, while the remainder of the sample took them at the start or the end of the meal.

Table 2 Patients' perception of their compliance with physiotherapy, exercise, enzyme and vitamin regimens

\begin{tabular}{lllll}
\hline & About right & Not enough & Too much & Don't know \\
\hline Physiotherapy $(\mathrm{n}=60)$ & $40(67)$ & $15(25)$ & $0(0)$ & $5(8)$ \\
Exercise $(\mathrm{n}=55)$ & $20(37)$ & $32(58)$ & $0(0)$ & $3(5)$ \\
Enzymes $(\mathrm{n}=60)$ & $47(78)$ & $5(8)$ & $2(4)$ & $6(10)$ \\
Vitamins $(\mathrm{n}=45)$ & $4(9)$ & $19(42)$ & $1(2)$ & $21(47)$ \\
\hline
\end{tabular}

Values in parentheses are percentages. (d) Vitamins: only 45 of the patients were prescribed vitamins. Of these, 21 always took their vitamins, 16 usually did, seven occasionally did, and one never did.

Overall, for all four treatments 18 patients were fully compliant, eight failed to do anything regularly, and the remaining 34 complied, to varying degrees, with the treatments.

Twenty patients reported that they never took non-prescribable medication, 33 did occasionally, and seven usually self-prescribed. These medications included vitamins and "over the counter" cough remedies.

Patients' perception of compliance (table 2)

(a) Physiotherapy: most patients $(n=40)$ considered their daily amount of physiotherapy to be about right, but 15 believed that they did insufficient physiotherapy. There were no patients who thought they did too much physiotherapy and five were unsure.

(b) Exercise: only 20 patients believed they were exercising sufficiently, 32 considered they were doing too little, none reported doing too much exercise, and three didn't know.

(c) Enzymes: most patients $(n=47)$ believed their enzyme intake was sufficient. Of the remaining 13 patients, five reported insufficient intake while excess intake was recorded by two, and six didn't know.

(d) Vitamins: only four patients thought their intake was correct; 19 thought they did not take enough vitamins, one patient considered the intake to be too much, while 21 patients did not know whether their intake was correct.

\section{Reasons given by patients for poor compliance}

(table 3)

Three common reasons could be recorded for non-compliance with each treatment. Twenty seven patients believed they were well without treatment; more than one third considered their disease to be less serious than others with cystic fibrosis, and 12 believed exercise could replace physiotherapy. Embarrassment and interference with social life were additional

Table 3 Reasons for poor compliance with physiotherapy, exercise, enzyme, and vitamin regimen

\begin{tabular}{lr}
\hline Predominant reasons for poor compliance & $n$ \\
\hline Physiotherapy ( $\mathrm{n}=60$ ): & \\
Well without physiotherapy & $27(45)$ \\
Not enough time & $24(40)$ \\
Can't be bothered & $24(40)$ \\
Less serious than others & $21(37)$ \\
Interrupts social life & $13(22)$ \\
Simply forget & $12(20)$ \\
Exercise instead & $9(15)$ \\
It's embarrassing & \\
Exercise ( $n=55):$ & $21(38)$ \\
Not enough time & $19(35)$ \\
Can't be bothered & $16(29)$ \\
Simply forget & \\
Enzymes (n=60): & $27(45)$ \\
Simply forget & $16(27)$ \\
It's embarrassing & $7(12)$ \\
Can't be bothered & $7(12)$ \\
Interrupts social life & \\
Vitamins (n=45): & $26(58)$ \\
Simply forget & $13(29)$ \\
Can't be bothered & \\
\hline
\end{tabular}

Values in parentheses are percentages. 
reasons for poor compliance with pancreatic enzyme therapy.

\section{COMPLIANCE: DEMOGRAPHIC AND CLINICAL VARIABLES}

Patients complied better with physiotherapy if they received help with it $(p=0.02)$ or produced large amounts of sputum $(p=0.02)$. The remaining clinical and demographic variables were not associated with levels of compliance.*

PREDICTIONS OF COMPLIANCE BY PHYSIOTHERAPIST AND PHYSICIAN

The physiotherapist and physician involved in the daily care of the patients correctly judged the degree of compliance with physiotherapy for $69 \%$ and $66 \%$ of patients, respectively. Condensing the six compliance categories into three gave correct predictions of $83 \%$ and $75 \%$ for physiotherapist and physician, respectively. Compliance with exercise was accurately predicted by the physiotherapist in $68 \%$ of patients, and by the physician in $67 \%$.

\section{Discussion}

Previous studies have consistently shown overall compliance rates with treatment of $50 \% .{ }^{11-14}$ In our study compliance with treatment and advice differed for each of the four treatment types: physiotherapy, exercise, pancreatic enzymes, and vitamin supplements. Compliance with physiotherapy and vitamin taking was less than the reported adherence to pancreatic enzyme taking and exercise in our patients. Our study suggests that patients may use their immediate symptoms as "barometers" to decide when to discontinue or continue treatment. Patients therefore focus on the short term rather than the long term benefits of treatment. This is emphasised by the fact that the lowest adherence rates occurred when there was no immediate risk or discomfort associated with poor compliance. Conversely, compliance improves when the treatment provides immediate benefits that patients can recognise. Compliance with enzyme regimens is high in order to avoid steatorrhoea, but low with vitamin therapy which has no apparent benefit. Only half of our patients reported that their chest felt better immediately after physiotherapy compared with $70 \%$ who perceived an immediate improvement following exercise. Patients reporting immediate benefits complied more than those experiencing no immediate improvement. This supports the suggestion that patients who believed that their treatment was beneficial were more likely to comply. ${ }^{8}$

The degree of compliance may be influenced by patient perception and understanding of the requirements of self treatment. This was evident in this study where $75 \%$ of patients exercised to a beneficial level, but only $37 \%$ considered this was sufficient. This is in

* Data available from authors on request. accordance with currently held views that exercise is compatible with a healthy lifestyle. In contrast, only half the patients were considered compliant with physiotherapy, yet $67 \%$ believed that they did enough. The major reasons for poor adherence with physiotherapy were that patients believed they were well or that the severity of their disease was less than that of others. Exercise was considered an alternative to physiotherapy in $20 \%$ of patients. These results confirm the finding that physiotherapy is the least tolerated aspect of treatment, as reported by both children and their parents, ${ }^{15}$ with adherence rates between $40 \%$ and $54 \%$ whether performed by parent or patient. ${ }^{610}$ Exercise may have been better complied with because, unlike physiotherapy, it is probably more acceptable to adults with cystic fibrosis and can be shared with their peers.

The demographic details of the patients had no influence on compliance apart from physiotherapy, where greater adherence was seen in those who received help or produced large volumes of sputum. Similarly, in paediatric clinics in North America parental compliance with antibiotic treatment was not associated with demographic and severity variables. ${ }^{578}$ In contrast, based on parental (for young children) and patient reporting, greater adherence to antibiotic and vitamin regimens correlated with lower Shwachman scores. ${ }^{6}$

Physicians have previously been reported to be poor at recognising patients who are compliant or non-compliant with the taking of medication, ${ }^{1617}$ although a director of a paediatric cystic fibrosis clinic correctly identified requirements for antibiotic treatment in $80 \%$ of cases. ${ }^{5}$ In this study both the physician and the physiotherapist differentiated between compliant and non-compliant patients for exercise and physiotherapy in most cases. Accurate predictions of compliance made by those involved in care of the patients probably results from a high level of continuing medical care and lifelong informal contact with the patient and family. This ability to predict compliance did not influence the level of adherence by patients, but it may assist the carers in assessing efficacy of treatment.

It may be unrealistic to expect young adults with cystic fibrosis to follow absolutely treatment advice as they attempt to strike a balance between their needs and the daily time consuming treatment regimens. This study found no associations between demographic or clinical variables and compliance with treatment. Severity of disease and the long term benefits of treatment regimens may not ensure compliance if the patient does not share the perceptions of the carers.

Compliance may be improved by offering patients the choice of treatments they prefer. We have previously shown that, when patients are given a choice between physiotherapy alone, exercise alone or the two combined, two thirds preferred the latter option. ${ }^{18}$

A crucial time when compliance needs to be enhanced is when patients are transferring from paediatric to adult care. Although patient independence and self involvement are 
encouraged, the interest and support from family and partners are crucial.

1 British Paediatric Association Working Party. Cystic fibrosis in the United Kingdom 1977-85: an improving picture. $B M \mathcal{F} 1988 ; 297: 1599-602$.

2 Phelan P, Hey Ed. Cystic fibrosis mortality in England and Wales and in Victoria, Australia 1976-80. Arch Dis Child Wales and in Victo

$1984 ; 59: 71-83$.
3 Warwick WJ. Prognosis for survival with cystic fibrosis: the effects of early diagnosis and cystic fibrosis centre care. Acta Paediatr Scand [Suppl] 1982;301:27-31.

4 Nielson OH, Schiotz PO. Cystic fibrosis in Denmark in the period 1945-1981; evaluation of centralised treatment. Acta Paediatr Scand [Suppl] 1982;301:107-19.

5 Meyers A, Dolan TF, Mueller D. Compliance and selfmedication in cystic fibrosis. Am $\mathcal{J}$ Dis Child 1975;129:1011-3.

6 Passero MA, Remor B, Salomon J. Patient-reported compliance with cystic fibrosis therapy. Clin Pediatr pliance with

7 Patterson JM. Critical factors affecting family compliance with home treatment for children with cystic fibrosis. Family Relations 1985;34:79-89.

8 Czajkowski DR, Koocher GB. Medical compliance and coping with cystic fibrosis, 7 Child Psychol 1987:28:311-9.

9 Strauss GD, Wellisch DK. Psychosocial adaptation in older cystic fibrosis patients. $\mathcal{F}$ Chronic Dis 1981;34:141-6.

10 Shepherd SL, Hovel MF, Harwood IR, Granger LE, Hofstetter CR, Molgaard C, et al. A comparative study of the psychosocial assets of adults with cystic fibrosis and the psychosocial assets of adults with cystic
their healthy peers. Chest 1990;97:1310-6.

11 Haynes RB, Taylor DW, Sacket DL. Compliance in health care. Baltimore: Johns Hopkins University Press, 1979.

12 Ley P. Towards better doctor-patient communication: contributions for social and experimental psychology. In: Bennett $\mathrm{AE}$, ed Communications between doctors and patients. London: Nuffield Provincial Hospitals Trust, 1976.

13 Ley P. Communicating with patients: improving communication, satisfaction and compliance. London: Croom Helm 1988 .

14 Barofsky I. The chronic psychiatric patient in the community. New York: Plenum, 1980.

15 Burton L. The family life of sick children. A study of families coping with chronic childhood disease. Boston: Routledge and Kegan Paul, 1975.

16 Mushlin AI, Appel FA. Diagnosing potential non-compliance. Arch Intern Med 1977;137:318-21.

17 Wardman AG, Knox AJ, Muers MF, Page RL. Profiles of non-compliance with antituberculous therapy. $\mathrm{Br} \mathcal{F} \mathrm{Dis}$ Chest 1988;82:285-9.

18 Bilton D, Dodd M, Abbott J, Webb AK. The benefits of exercise combined with physiotherapy in the treatment of adults with cystic fibrosis. Respir Med 1992;86:507-11. 


\section{Appendix}

\section{The Manchester Cystic Fibrosis Compliance Questionnaire}

The following questions ask you about your treatment. So that we can assess how effective your treatment is, please answer all the questions honestly.

1 How often do you attend the CF outpatient clinic? How often do you attend as an inpatient?

15 With a MAIN meal do you take them: Tick one box only

Throughout the meal.

Only at the beginning of the meal.

Physiotherapy

2 What age were you when you started having physiotherapy?

Only at the end of the meal.

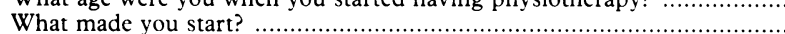

Do you have help with your physiotherapy? $\quad$ Yes

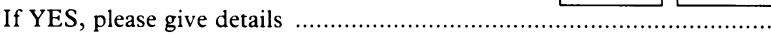

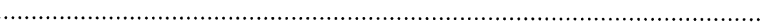

4 How many times each day, has it been agreed, that you should do your

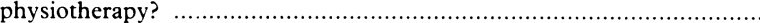

5 Over the last three months, which of the following statements best describe you?

Tick one box only

I do my physiotherapy once or twice each day, every day.

Occasionally I miss one or two days physiotherapy.

I often miss one or two days physiotherapy.

I often miss several days physiotherapy.

The only time I do my physiotherapy is when I feel unwell.

I never do my physiotherapy.

6 Please tick the boxes which best describe you. When I miss my physiotherapy it is usually because:

Tick as many boxes as you like

I feel well without treatment.

It interferes with my social life.

There isn't enough time.

I have to rely on someone to help me.

I simply forget.

My CF isn't as serious as most of the other CF patients.

It interferes with family routine commitments.

I can't always be bothered.

I don't believe that it does me any good.

I have too many different treatments to attend to, and physiotherapy is the least important of them.

It makes me feel worse.

I don't fully understand why I need to do physiotherapy.

I do plenty of exercise, so I don't need to do physiotherapy.

I don't know how to do it.

I have difficulty doing my own physiotherapy.

I resent having to do it.

It's embarrassing.

7 Do you think that the amount of physiotherapy you do is: Tick one box only

\begin{tabular}{|l|l|l|l|l|l|l|}
\hline About right & Too much enough \\
\hline
\end{tabular}

16 Do you take them with snacks?

Tick one box only

\begin{tabular}{|l|l|l|l|l|l}
\hline Never & Occasionally \\
\hline
\end{tabular}

17 If I don't take my enzymes it is usually because:

Tick as many boxes as you like

I only take them when they are given to me.

I am embarrassed to take them in front of other people.

I don't like the taste.

I have difficulty swallowing them.

I have difficulty getting repeat prescriptions.

I simply forget.

My body occasionally needs a rest from medication, otherwise I may become immune to them, and they will not work when I really need become immune to them, and they.
them.

I only take enzymes when I

I resent having to take them.

I don't want my friends colleagues to know that I hav

My CF isn't as serious as most of the other CF patients.

I have too many different treatments to attend to, and this is the least important of them.

I don't believe that they do me any good.

I can't always be bothered.

They make me feel worse.

It interferes with my social life.

18 Do you think that your pancreatic enzyme intake is: Tick one box only

\begin{tabular}{|l|l|l|l|l|l|l|}
\hline About right & Doo mon't know \\
\hline
\end{tabular}

19 Do you eat whatever you like?

Do you eat a fat-free diet?

Do you eat a vegetarian diet?

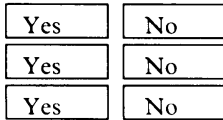

\section{Vitamins}

20 Are you prescribed vitamins?

Yes No

21 If YES, what has been prescribed, and how often should you take them?

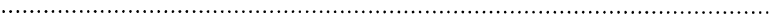

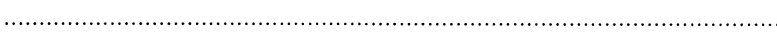

22 How often do you actually take your vitamins? Tick one box only

\section{Exercise}

8 Do you do any exercise? Yes No

\begin{tabular}{|l|l|l|l|}
\hline Never Uccasionally \\
\hline
\end{tabular}

9 If YES, what do you do and how often?

23 If I don't take my vitamins as prescribed it is usually because: Tick as many boxes as you like

I only take them when they are given to me.

I don't like the taste.

I have difficulty swallowing them.

I take more than has been prescribed for me.

I have difficulty getting repeat prescriptions.

They make me feel worse.

I simply forget.

My body occasionally needs a rest from medication, otherwise I may become immune to them, and they will not work when I really need them.

I only take vitamins when I feel unwell.

I resent having to take them.

I don't want my friends colleagues to know that I have CF

I don't fully understand why I need to take them.

My CF isn't as serious as most of the other CF patients.

I have too many different treatments to attend to, and this is the least important of them.

I don't believe that they do me any good.

I can't always be bothered.

24 Do you think that your vitamin intake is: Tick one box only

\begin{tabular}{|l|l|l|l|l|l|l|l|l}
\hline About right & Too much \\
\hline
\end{tabular}

12 Do you think your present level of exercise is: Tick one box only

\begin{tabular}{|l|l|l|l|l|l|l}
\hline About right & Too much \\
\hline
\end{tabular}

\section{Pancreatic enzymes}

13 Do you take your enzymes with a MAIN meal? Tick one box only

\begin{tabular}{|l|l|l|l|l|}
\hline Never & Occasionally \\
\hline
\end{tabular}

14 How many do you usually take with a MAIN meal?

25 Do you take any medication which has not been prescribed by a doctor?

\begin{tabular}{|l|l|l|l|l|l|l|l}
\hline Never & Occasionally \\
\hline
\end{tabular}

26 What do you take, and how often?

27 Why do you take it? 